\title{
Economic vs environmental isocost and isoperformance curves for the seismic and energy improvement of buildings considering Life Cycle Assessment
}

\author{
Linda Giresini ${ }^{1}$, Flavio Stochino ${ }^{2}$ and Mauro Sassu ${ }^{3}$ \\ ${ }^{1}$ Department of Civil and Industrial Engineering, University of Pisa, Largo Lucio Lazzarino, 1, 56100, Pisa, \\ Italy; linda.giresini@unipi.it \\ ${ }^{2,3}$ Department of Civil, Environmental Engineering and Architecture, University of Cagliari, Via Marengo, 2, \\ 09123 Cagliari, Italy; fstochino@unica.it,msassu@unica.it.
}

\begin{abstract}
A methodology to quantitatively assess the improvement of seismic and energy performance of masonry buildings through retrofitting interventions is here proposed. The approach is developed at mesoscale level, considering entire façades with openings and taking into account Life Cycle Assessment (LCA). The costs of retrofitting interventions that couple effects of seismic and thermal improvement (called integrated interventions/approaches) are different whether only the construction phase or the entire life cycle of the building is considered. Therefore, it is necessary to estimate at what extent it is correct to neglect LCA in the analysis of integrated approaches. In this paper, the analysis of three masonry façades is performed with and without LCA. Traditional (insulating panels, diatons, ferro-cement) and more innovative interventions (carbon and glass fiber reinforced polymer composites) are considered. For the comparison, isocost and isoperformance curves, which determine both the economic (Euros) and environmental costs $\left(\mathrm{kg} \mathrm{CO}_{2 \mathrm{eq}}\right)$ for each intervention, are discussed. The comparison shows the necessity of always considering LCA for a reliable assessment: some retrofitting interventions are the most expensive in the construction phase but they result the most convenient in economic terms and in the amount of $\mathrm{CO}_{2 \text { eq }}$ emissions.
\end{abstract}

\section{Introduction}

Nowadays, developed countries standards as ISO 14040 [1] and Eurocodes [2] require high levels of performance in both seismic and energy field. These requirements are more and more demanding and the technical solutions 
needed to meet them imply high economic and environmental costs. At the same time, a large number of studies and best practice have been developed to save energy or to introduce sensors or active gears to enhance the comfort in buildings [3]-[5]. Moreover, the impact of retrofitting techniques, especially for existing masonry buildings, is not easy to predict. Indeed, from a structural point of view it is difficult - and sometimes not significant - to model the global behavior due to poor connections between structural elements [6]. In this case, local analyses are more significant [7]-[11]. From an energy point of view, there is an analogous gap between the availability of calculation methods and the real knowledge of the components inside the walls. Sometimes it is preferable, in professional practices, the adoption of simple calculation methods of thermal performances based on standard codes. The need of integrating energy evaluations with structural retrofitting is of high priority in seismic prone areas [12], [13]. In any case, the use of sustainable solutions in masonry structures, either traditional or more innovative such as the use of bionatural aggregates [14], is to be pursued. The impact of retrofitting solutions is generally strong at both economic and environmental level. That is why the European Union financed many projects on gathering knowledge in sustainable procedures to reduce such an impact in the building sector. Indeed, the building sector consumed $40 \%$ of the total final energy in Europe and produced $36 \%$ of $\mathrm{CO}_{2}$ emissions throughout the whole building life cycle [15]. Often, the retrofitting of a building is aimed at only addressing a single issue, for instance the reduction of seismic vulnerability. Sometimes the building is uniquely improved in terms of energy performance; severe damages can then occur even under not extreme earthquakes, as occurred in Italy during 2012 earthquake (Figure 1). In practical design of retrofitting techniques, only sporadic cases follow a multi-disciplinary approach, due to the lack of proper standard protocols. These deficiencies must be addressed since it is convenient to save resources for the whole planet, which currently faces the problem of emissions of greenhouses gasses and global warming. In the civil construction sector, the need of new building concepts arose, and it resulted in the proposal of low energy and even self-sufficient houses [16]. This approach naturally implies a life cycle assessment (LCA) of the building, whose application method is not unique, as highlighted in the ISO 14040 standard series $[1]$.

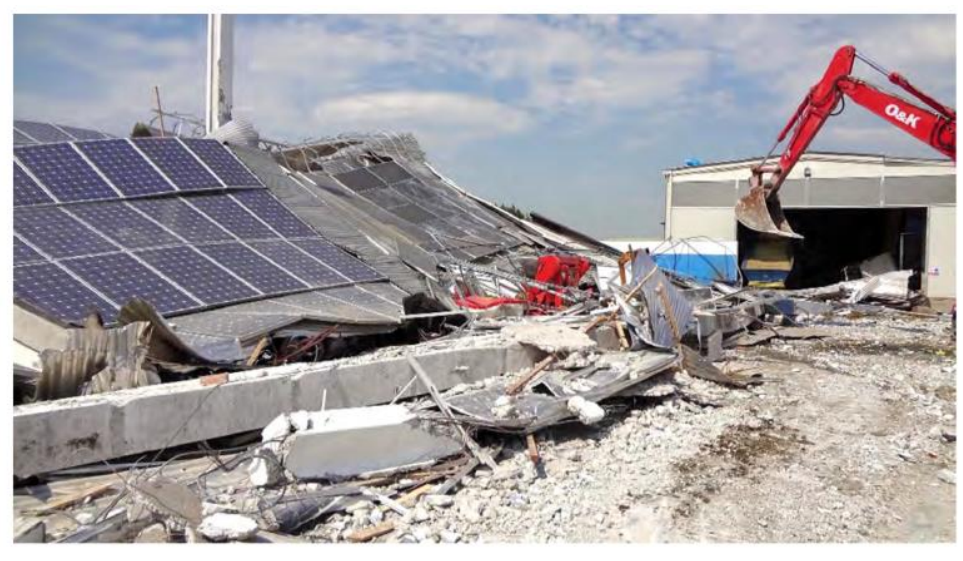

Courtesy Telestense TV, Ferrara Italy - from "TV giomale", May $21^{\text {st }} 2012$ 
The sustainability issue, with its three aspects (economic, environmental and social) should be incorporated in designing retrofit techniques to improve the energy performance of the building. In line with this perspective, several works were recently proposed describing how to effectively combine energy efficiency and seismic resilience [17]. Such a combination permits to design the so called "integrated interventions", namely those that perform at the same time improvements in terms of seismic and energy performance. Other contributions were more specifically devoted to masonry constructions, considering the single masonry panel [18], [19] or the entire façade [20]. The latter aims at applying the mesoscale approach - that is at the level of the façade including its openings - in the definition of integrated interventions. The present paper broadens the scopes highlighted in [20] taking into account the LCA in the evaluation of economic and environmental costs. Moreover, it includes the combination of integrated interventions to optimize their outcomes. New curves, called isoperformance curves, are used for the comparison between the two approaches.

The paper is organized as follows: Section 2 describes the steps for the design of integrated interventions with LCA at mesoscale level. In Section 3 the individual and combined integrated interventions are selected, whilst Section 4 gives specific information about LCA. In Section 5 the proposed methodology is applied to a case study (masonry building located in Italy) yielding to isocost curves in environmental and economic terms.

For the sake of clearness, the term "environmental" is here referred to the consumption in terms of $\mathrm{kg}$ of $\mathrm{CO}_{2}$ equivalent. Moreover, the energetic performances of the building are referred to classical and periodic thermal transmittances, both taken into account. Finally, Section 6 illustrates the same analysis but considering LCA and discusses isoperformance curves in terms of their utility in the decision-making.

\section{Integrated interventions considering Life Cycle Assessment (LCA) at mesoscale level}

\subsection{Procedure for the design of integrated interventions}

The steps to follow in the mesoscale procedure (related to single façades) presented in [20] are listed:

1. Acquisition of thermal and mechanical parameters of the façade in the as-built configuration;

2. Definition of integrated interventions with positive effects on either the seismic response, or the energy performance or both of them (Section 4).

3. LCA with reference to the previously proposed integrated interventions.

4. Identification of a seismic performance indicator (variation of base shear strength $\Delta V$ and variation of ductility $\Delta \mu$ ) and of an energy performance indicator (variation of thermal transmittance $\Delta U$ and of periodical thermal transmittance $\Delta U_{p}$ ).

5. Economic and environmental isoperformance curves showing, for each intervention, the related cost.

6. Economic and environmental isocost curves reporting the relationships between the thermal indicator $(\Delta U)$ and the structural indicators $(\Delta V$ or $\Delta \mu)$. These curves represent the capacity of the retrofitted buildings. 
7. Definition of dimensionless parameters $c_{U}$ and $c_{R}$, defined in [19], to identify the "demand" of thermal and seismic performances respectively, with the expressions:

$$
c_{U}=\frac{D D_{i}}{D D_{\max }} ; c_{R}=\frac{P G A_{i}}{P G A_{\max }}
$$

where $P G A_{i}$ is the seismic peak ground acceleration at the specific site of the building, $P G A_{\max }$ is the maximum value in the reference area; $D D_{i}$ is the degree day of the specific site of the building and $D D_{\max }$ the maximum value in the reference area. The heating/cooling degree day $(D D)$, is a measurement designed to quantify the demand for energy needed to heat a building/for air conditioning. The reference area can be a district, a region or a State. These values are given for different construction sites respectively by [21] and [22].

8. Definition of the demand curves through the expressions:

$$
\Delta U=\alpha \frac{c_{R}}{c_{U}} \Delta V ; \Delta U=\alpha \frac{c_{R}}{c_{U}} \Delta \mu
$$

where $\alpha$ is a tuning parameter that can be established by the decision-maker according to political, social or stakeholder reasons [19]. The tuning parameter $\alpha$ is a positive number which can be seen as an additional parameter that modifies the relationship between the thermal and seismic indicator according to necessities out of seismic and energy demands. For example, if the stakeholder prefers to guarantee a higher level of structural safety due to tax incentives or other reasons, $\alpha$ should be less than 1, increasing the structural demand (indeed, in this case, it can be seen as fictitious increment of $c_{R}$ ). Without any political/social/stakeholder need, the tuning parameter can be assumed equal to 1 .

9. Use of capacity curves (obtained with step \# 6) and demand curves (obtained with step \#8) to iden tify the performance of the intervention given a specific economic budget and/or an environmental maximum emission.

The step that differs from the procedure already illustrated in [20] are the third and the fifth ones, which considers the LCA of the intervention and the corresponding isoperformance curves. Moreover, this paper introduces the periodical thermal transmittance $\Delta U_{p}$ besides the thermal transmittance $\Delta U$ used in [19], [20].

\subsection{Determination of isocost curves}

For the calculation of the isocost curves, two models are employed: one for the seismic indicators (base shear and ductility) and another for the energy indicators (thermal transmittance and periodic thermal transmittance). The seismic indicators are determined by modelling the masonry façades through macro-elements or brick/shell finite elements. An in-plane analysis is performed considering a distribution of force either uniform or proportional to first vibration mode or both of them. Considering the displacement of a control point located at the top and center of the façade, the force-displacement relationship is obtained and from it the maximum shear force $V$ and the 
ductility value $\mu$ can be inferred. The sub-index 0 indicates the as-built state, whereas 1 indicates the parameter after the integrated intervention. Thus, the seismic performance indicators are:

$$
\Delta V=\frac{\left|V_{1}-V_{0}\right|}{V_{0}} ; \Delta \mu=\frac{\left|\mu_{1}-\mu_{0}\right|}{\mu_{0}}
$$

As for the thermal transmittance, the energy indicator comes from the calculation of the thermal transmittance $U$, defined as rate of transfer of heat through a unitary surface with a difference of temperature of $1^{\circ} \mathrm{C}$. It is calculated as function of the thermal resistance layers composing the wall by following the indications of UNI EN ISO 6946:2008 [23]. The thermal conductivity $\lambda_{i}$ is obtained by UNI 10351:1994 [24].

Analogously to the seismic indicator, the energy performance indicators are the ratio between the variation of thermal performance to the initial value:

$$
\Delta U=\frac{\left|U_{1}-U_{0}\right|}{U_{0}} ; \Delta U_{p}=\frac{\left|U_{p 1}-U_{p 0}\right|}{U_{p 0}}
$$

Each intervention entails a reduction of the thermal transmittance $U$ (or analogously of the periodic thermal transmittance $\left.U_{p}\right)$ and the parameter $\Delta U\left(\Delta U_{p}\right)$ allows to measure its entity. The periodic transmittance, whose definition is given in UNI EN ISO 13786 [25], expresses the capacity of a building component of mitigating and delaying during time the thermal flux coming from outside during the 24 hours. Whilst the normal transmittance is useful for the winter period (steady state), the periodic transmittance is significant during summer (transient state).

The mesoscale approach considers the openings in the façades calculating a unique value of thermal transmittance representative of the whole façade [20], capable to take into account the thermal transmittances of the walls $U_{m}$ and of the windows $U_{w}$ :

$$
U=\frac{A_{m} \cdot U_{m}+A_{w} \cdot U_{w}+l \cdot \Psi}{A_{m}+A_{w}}
$$

in which $A_{m}$ is area of the masonry element and $A_{w}$ is the area of the window. Moreover, $l$ is the perimeter of the wall and $\Psi$ the linear thermal transmittance calculated with UNI EN ISO 10211:2008 [26]. For the periodic transmittance is valid:

$$
U_{p}=\frac{A_{m} \cdot U_{p m}+A_{w} \cdot U_{w}+l \cdot \Psi}{A_{m}+A_{w}}
$$

Therefore, first the thermal transmittance of masonry $U_{m}$ (which can be normal periodic) and windows [27] is calculated in the as-built and in the retrofitted configuration and after the energy indicator is obtained through Eqs. (4). 
The isocost curve represents a sort of capacity curve for the retrofitting solution, in the sense that it indicates the structural and thermal improvement associated to each retrofitting technique. It is obtained with the following procedure:

1) An economic budget (in euros) and/or an environmental impact (in $\mathrm{kg}$ of $\mathrm{CO} 2 \mathrm{eq}$ ) is fixed;

2) Each point of the isocost curve is univocally identified by the value of seismic performance indicator associated to the value of energy performance indicator, each pair defined for a single intervention;

3) The regression curve is obtained interpolating the results through the optimization tool called lsqnonlin implemented in MATLAB [28], which makes use of the least square method. In the case under study, an hyperbolic function $\Delta U\left(\gamma_{1}+\Delta V\right)=\gamma_{2}$ is used and the lsqnonlin tool provides the values of the scalar parameters $\left(\gamma_{1}, \gamma_{2}\right)$.

Figure 2 displays the described procedure through which an example of environmental isocost curve is obtained for seven different retrofitting techniques (reinforced diatons + insulating panels, GFRP nets + insulating panels, etc.).
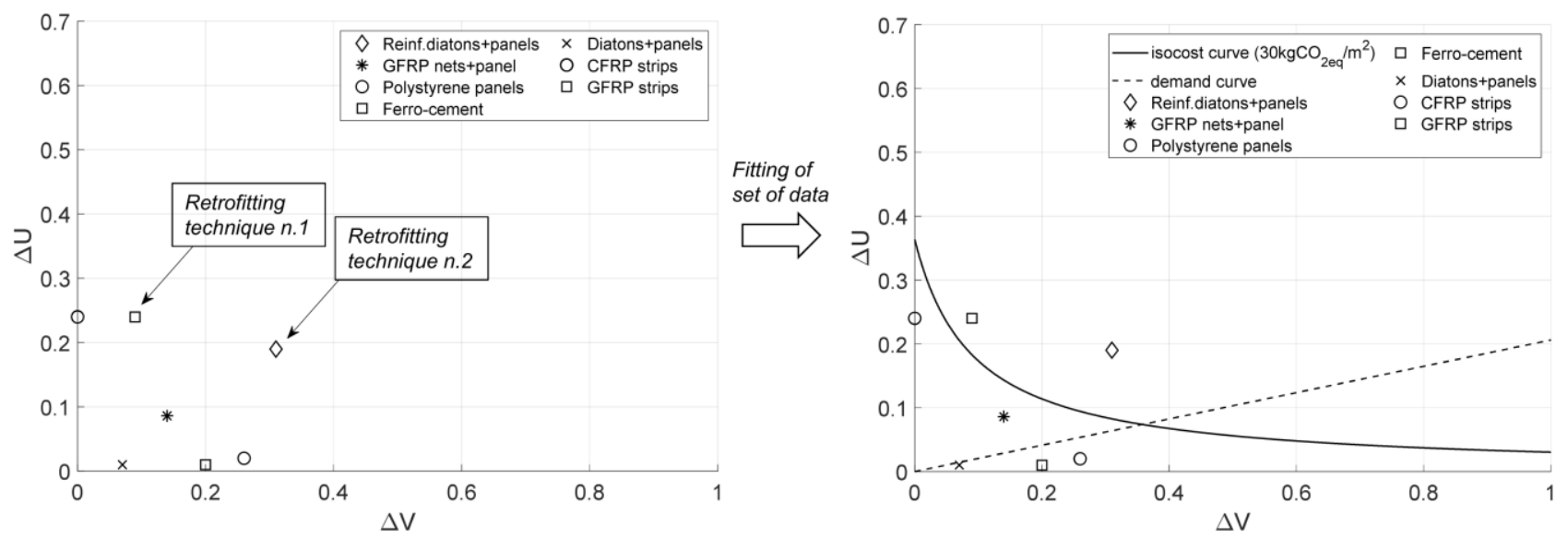

Figure 2 - Procedure to define the economic and environmental isocost curves.

\subsection{Extension of the method to other building types and local analysis}

The methodology here presented can be easily extended from masonry buildings to other structures, such as r.c., timber and steel buildings. The extension is possible by properly adapting the selection of the seismic performance indicator, which can be, for instance, the percentage reduction of an interstorey drift when a global analysis is considered. Moreover, the methodology is also applicable to non-structural elements contained in the building or parts of it. This is the case of local analyses, rather relevant for existing masonry buildings. Among local mechanisms typical of masonry buildings, there is overturning, horizontal and vertical bending, corner mechanism 
[8], [29], etc.; these mechanisms are activated when the connections between vertical walls and between horizontal diaphragms and walls are not efficient [6], [30]. Kinematic and rocking analyses which treat non-structural elements or local mechanisms as rigid blocks may be used [31]-[34]. The methodology is then easily adaptable since, in place of $\Delta V$ or $\Delta \mu$, one can use other seismic performance indicators, such as the increase of displacement capacity or a safety index given by the ratio of displacement capacity to displacement demand. The latter parameters can be obtained through standardized procedures such as those proposed in the Italian standards [35].

\section{Selection of integrated interventions and their combination}

This section proposes examples of common interventions for seismic retrofitting and thermal insulation of masonry constructions. In particular, two categories of interventions are taken into account: single and combined interventions. Single interventions usually cause a predominant improvement either in the seismic response or in the energy performance. In view to optimize the performance, the opportunity of combined interventions arises. Therefore, the following solutions are proposed:

Single interventions (only structural or only thermal performance)

1. Insulating panels (polystyrene - cork or other components)

2. Ferro-cement on both wall layers

3. Fiber reinforced polymer composites (CFRP (Carbon Fiber Reinforced Polymers) strips, GFRP (Glass Fiber Reinforced Polymers) strips, GFRP nets)

4. Hoop steel frames in the openings with low energy impact glasses

The first three typologies are "smeared" interventions, whilst the fourth one is local.

\section{Combined interventions (integrated structural and thermal performances)}

5. Insulating panels + GFRP nets

6. Insulating panels + Hoop steel frames

7. Insulating panels + controlled-injection diatons

8. Insulating panels + reinforced diatons

\section{Life cycle assessment (LCA) in the integrated approach}

The LCA, also called cradle-to-grave analysis, is a well-known process to evaluate the environmental impact of manufactured products. The LCA also applies to the construction sector: the differences between its application to a generic element and a building are illustrated in [36]. As for the building sector, LCA considers the following stages: design, construction (including raw material process, products manufacture and distribution), use, demolition (final disposal of the building materials, their landfilling or recycle). Three types of energy are 
associated to these stages: embodied, operating and demolition energy [13], [37], [38]. In current practice, LCAs are performed by passing through four steps: goal and scope, Life Cycle Inventory (LCI), Life Cycle Impact Assessment (LCIA) and interpretation of the results. The procedure here proposed to design integrated interventions with LCA requires it as third step (Section 2) after the definition of technical solutions. It is worthy to highlight that buildings are special products and for them LCA is a challenging task. This is due to the long lifespan of a structure, to the numerous materials and processes involved, of different duration and function, to the evolution of functions over time because of maintenance and to the specificity of each building [39]. For these reasons, the LCA included in the procedure proposed for the integrated approach only uses results directly related to impact categories, without any normalization nor weighting. It seems the simplest and most objective approach [39].

Global warming is the impact category taken into account in this study. The unit of this EPD is $\mathrm{kg}$ of $\mathrm{CO}_{2}$ emitted in the atmosphere during the whole life cycle of the used products. That unit can be obtained, depending on the retrofitting interventions, from specific databases. For the present work, [40], [41] are used. The sustainability issue is strictly related to the economic terms (indeed the three aspects of sustainability, as discussed in the Introduction, are economic, environmental and social). The costs of each retrofitting intervention have to be computed referring to the product itself (e.g. the cost of 1 square meter of insulating panel), its installation for what concerns the construction phase. As for the use stage, the cost is related to the maintenance and refurbishment. The final step is the final disposal of the building material, that can be landfilled or recycled. This last step only considers the final disposal of the material used for the intervention (e.g. ferro-cement, GFRP strips, etc.) and neglects that of the base material. In other words, the demolition of the initial structure is not considered. In other words, when LCA is neglected, only the costs related to supply of materials and to labor of the first installation are accounted for. In case that a life cycle analysis is considered, additional economic and environmental impacts related to the use phase and final disposal are calculated analogously to what is done for the construction phase.

Moreover, special classes of buildings - such as schools, like the building of the case study in this paper - require the consideration of downtime costs, which can be significant if the retrofitting extends over several weeks of work. External retrofitting techniques, such as external earthquake resistant frames, would not involve these downtime costs and thus they result to be more economic and environmentally friendly.

The manpower is calculated through a labor cost of $35 € / \mathrm{h}$ multiplied by the time required for each intervention. All the data related to supply of materials and labor are obtained from official pricelists released to Italian engineers [42]. 


\section{Application of the integrated approach considering LCA}

\subsection{Description of the case study and initial performance indicators}

The case study on which the mesoscale analysis for integrated interventions applies is a three-storey high school located in Southern Italy. Three representative façades were selected for the analysis (Figure 3).

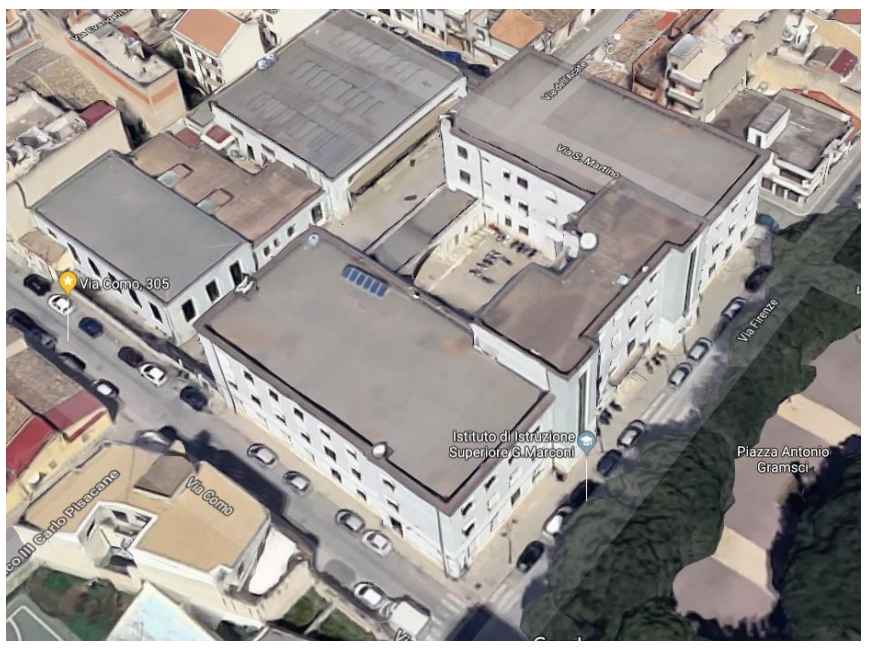

(a)

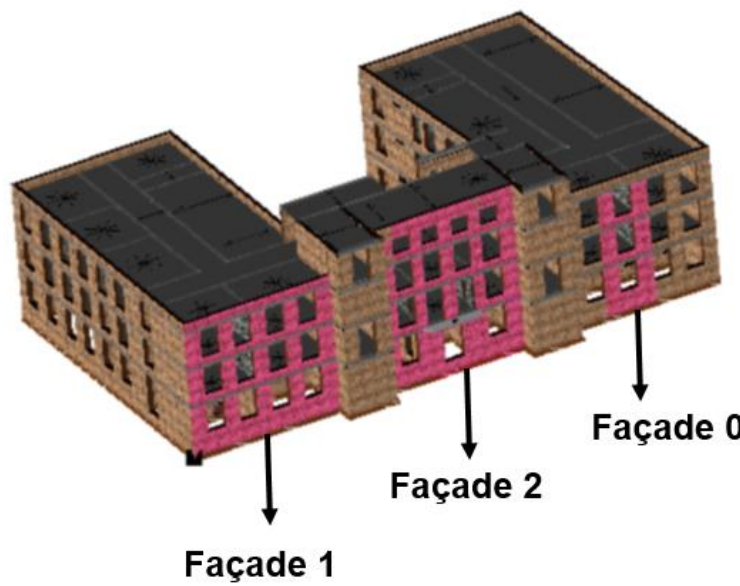

(b)

Figure 3 - The G. Marconi school located in Ragusa (Italy) (a); numerical model with the façades selected for the mesoscale analysis (b).

The C-shaped building is made of irregular stone masonry walls whose thickness varies from $70 \mathrm{~cm}$ (ground floor) to $50 \mathrm{~cm}$ (second floor). Its plan dimensions are about $60 \times 35 \mathrm{~m}^{2}$. The material has been mechanically characterized by experimental tests (endoscopies, double flat-jack tests, sliding tests, modified Sheppard test), obtaining an average compression strength of $0.14 \mathrm{MPa}$, shear strength (without normal force) of $0.10 \mathrm{MPa}$, elastic modulus $600 \mathrm{MPa}$, tangential modulus $200 \mathrm{MPa}$. The three façades are in-plane modelled through macro-elements of 20 $\mathrm{cm}$ average size. From them, by performing a non-linear static analysis with uniform force distribution through a commercial software [43], the initial seismic indicators are obtained for three façades (Figure 3b). The energy indicators are also calculated and results are summarized in Figure 4. Thus, both energetic and structural performance have been considered for the LCA assessment.

For the sake of brevity, the example will be discussed by adopting the variation of shear strength $\Delta V$ as seismic indicator. As for an example of ductility variation, the reader is referred to [20] for an analogous case.

It should be observed that for strategic buildings such as schools, in order to limit as much as possible the interventions inside the building to avoid interruption of use, low-impact retrofitting techniques should be recommended, as for instance external bracings properly connected to the existing building so that the seismic force is correctly transferred to the resisting frames [44], [45]. 


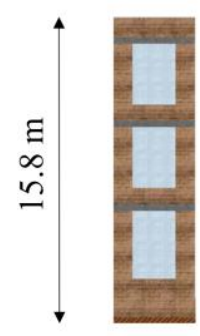

$4.0 \mathrm{~m}$

Façade 0



$$
4
$$

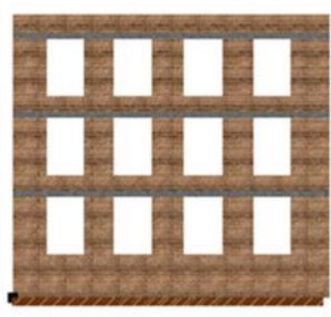

$17.8 \mathrm{~m}$

Façade 1

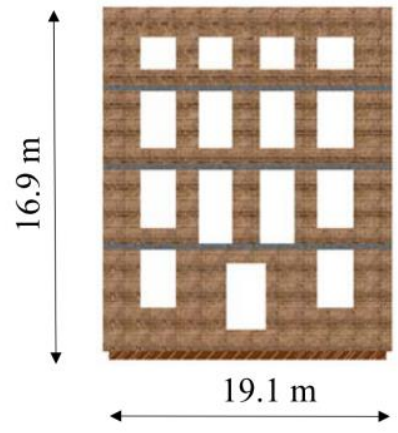

Façade 2

\begin{tabular}{ccc}
$\mathbf{V}_{\mathbf{0}}$ & 83 & $\mathrm{kN}$ \\
\hline $\mathbf{U}_{\mathbf{0}}$ & 2.93 & $\mathrm{~W} / \mathrm{m}^{2} \mathrm{~K}$ \\
\hline $\mathbf{U}_{\mathbf{p}, \mathbf{0}}$ & 2.21 & $\mathrm{~W} / \mathrm{m}^{2} \mathrm{~K}$
\end{tabular}

\begin{tabular}{lcc}
$\mathbf{V}_{\mathbf{0}}$ & 732 & $\mathrm{kN}$ \\
\hline $\mathbf{U}_{\mathbf{0}}$ & 2.72 & $\mathrm{~W} / \mathrm{m}^{2} \mathrm{~K}$ \\
\hline $\mathbf{U}_{\mathbf{p}, \mathbf{0}}$ & 0.96 & $\mathrm{~W} / \mathrm{m}^{2} \mathrm{~K}$
\end{tabular}

\begin{tabular}{lrc}
$\mathbf{V}_{\mathbf{0}}$ & 819 & $\mathrm{kN}$ \\
\hline $\mathbf{U}_{\mathbf{0}}$ & 2.66 & $\mathrm{~W} / \mathrm{m}^{2} \mathrm{~K}$ \\
\hline $\mathbf{U}_{\mathbf{p}, \mathbf{0}}$ & 0.91 & $\mathrm{~W} / \mathrm{m}^{2} \mathrm{~K}$
\end{tabular}

Figure 4 - Initial performance indicators for each façade.

\subsection{Isocost economic and environmental curves}

The isocost curves are initially calculated neglecting LCA, which is instead considered in Section 6 to make a comparison between the two cases with and without taking it into account. The isocost curves, obtained as described in step n. 6 of the proposed procedure (Section 2), are displayed in Figure 5 for the three façades.

Figure $5 \mathrm{a}, \mathrm{c}$, e reports the economic curves for façade 0,1 and 2 respectively. Analogously, Figure $5 \mathrm{~b}$, d, f shows the environmental curves for the same façades. The graphs also display the demand curves (step n. 8, Section 2) for two Italian sites: one is near the construction site, Catania (Sicily). A second site has been chosen to compare a high intensity seismic zone (Catania) with a low intensity seismic zone (Cagliari, Sardinia). The parameters of Equation (1) are $c_{U}=0.161$ (Catania); 0.192 (Cagliari) $-c_{R}=0.782$ (Catania); 0.182 (Cagliari). The demand curves are shown with dashed lines in Figure 5. The hyperbolic curves are obtained by interpolating the capacity values, computed for each intervention and for each level of investment.

With more details, for a given economic or environmental budget and for each intervention, the performance improvement ( $\Delta U, \Delta V$ see section 2.2) has been evaluated and reported in the figure as a dot. In this way, it is possible to compare different retrofitting strategies that have the same cost but different performance results. It should be noticed that some interventions, for instance ferro-cement and diatons, only imply a variation of strength when thickness increases, by following Italian standards [46], [47]. These graphs are of very simple use: one can quickly evaluate the increment of performance indicator for each intervention and for each unitary cost. 




(a)

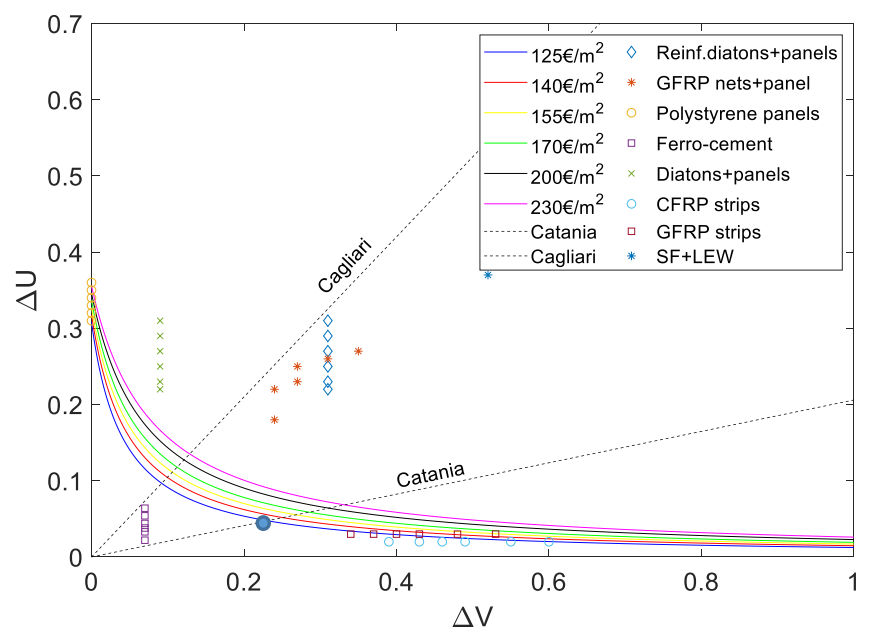

(c)

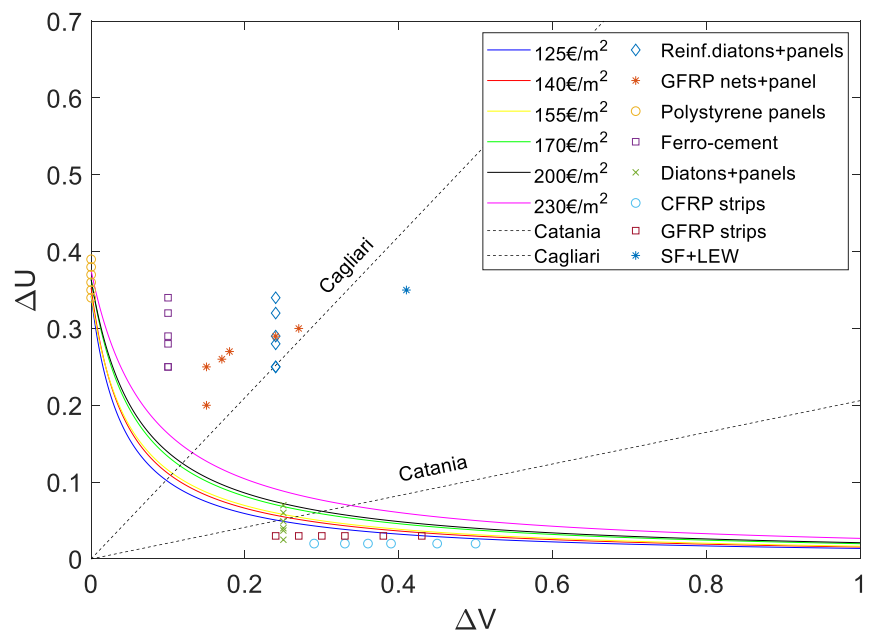

(e)

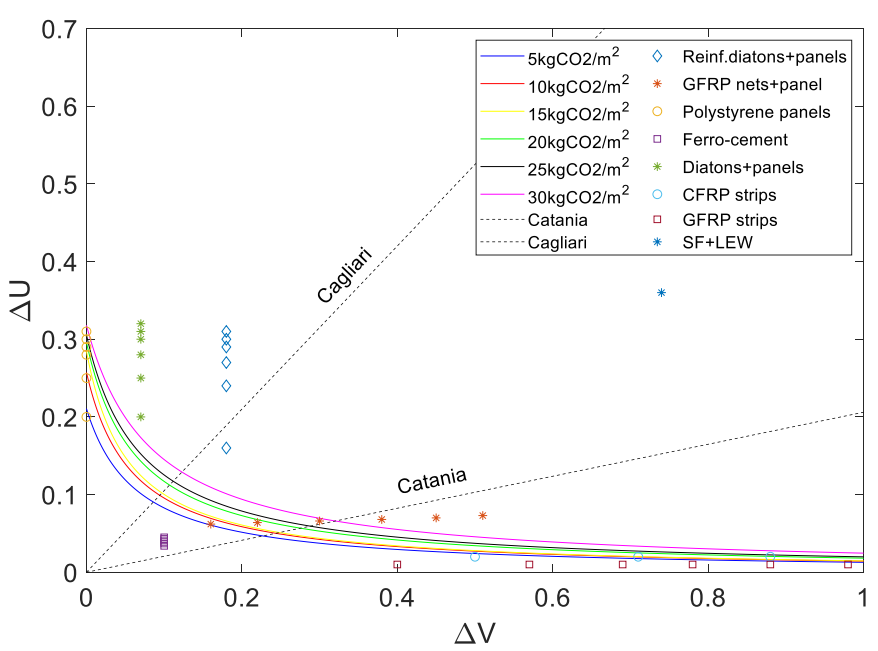

(b)

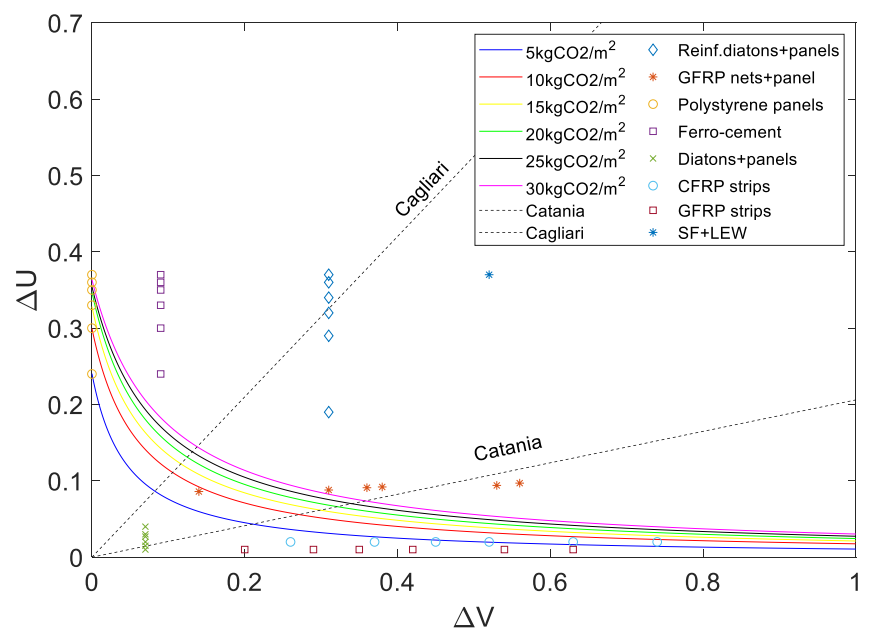

(d)

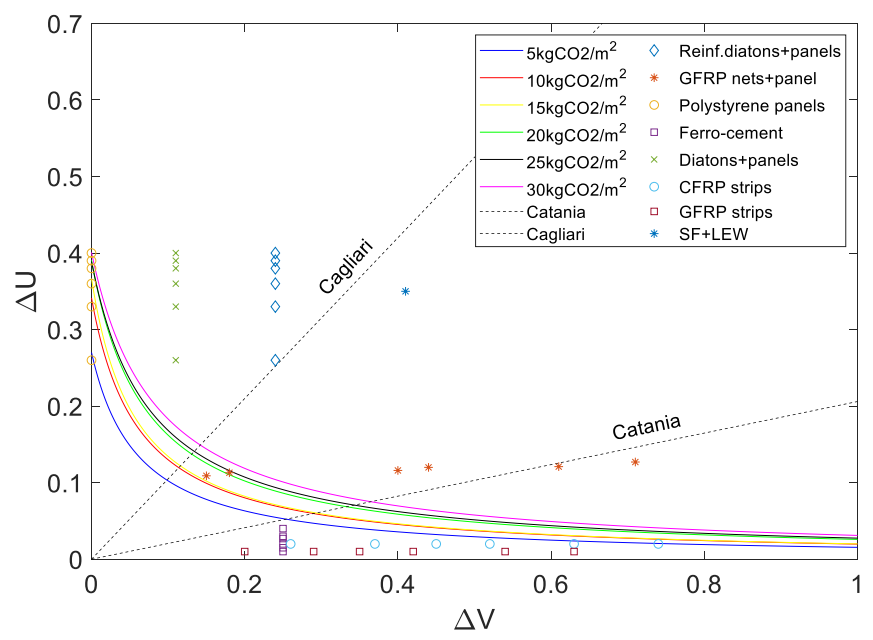

(f)

Figure 5 - Variation of transmittance-variation of base shear isocost curves: façade 0, economic (a) and environmental (b); façade 1, economic (c) and environmental (d); façade 2, economic (e) and environmental $(f)$. SF+LEW=hoop steel frame+low emittance windows. 
The target points are given by the intersection between demand and capacity curves (hyperbolic curves). For instance, with a budget of $125 € / \mathrm{m}^{2}$, façade 1 can reduce by $4 \%$ its transmittance and increase by $22 \%$ its base shear (capacity curve: blue curve, target point: blue dot, Figure 5c). This information is useful for both public administrations and private owners: they can be aware of the level of improvement attained in function of the available budget and type of intervention.

With reference to the target points, it can be observed that the seismic improvements for façades 1 and 2 are similar for Catania case (the construction site of the school). Indeed, the variation of base shear force is around $20 \%$ and $35 \%$. This increment is much more significant for the more slender façade 1 , where $\Delta V$ varies between $35 \%$ and $49 \%$. As for the transmittance, all the façades gives $\Delta U$ values between $5 \%$ and $40 \%$.

Looking at Figure 5, the following comments can be made:

- CFRP and GFRP give high performances, indeed the increment of base shear of façade 0 is about $90 \%$ and by about $40 \%$ for façades 1 and 2 ;

- Polystyrene insulating panels guarantee a reduction of transmittance by about $30 \%$ for all the façades, with limited variations of $\Delta U$ in function of the cost, due to the large windows area that limit the beneficial effect of the external coating. It is then reasonable to adopt this intervention only in a combined way: if the thickness increases, $\Delta U$ does not proportionally increase.

- The intervention with GFRP and polystyrene panels gives optimal results, with $\Delta V$ by $25 \%$ and $\Delta U$ by $22 \%$.

- By fixing a budget, therefore, the best combined interventions are the reinforced diatons plus polystyrene insulating panels and GFRP plus polystyrene panels. Moreover, these interventions give a relevant benefit in terms of energy saving calculated in 50 years of building life.

A particular comment is needed for the intervention based on the steel frame to install in the openings and the replacement of existing windows with low-emittance ones. This intervention, identified in the graphs of Figure 5 as "SF+LEW", is not included in the curve fitting of the capacity curves since its impact is hugely different from the other interventions. Indeed, the increase of the two performance ratios is by $35-40 \%$ for $\Delta U$ and at least by $40 \%$ for $\Delta V$ (for façade 2, whilst for façades 0 and 1 is respectively about $75 \%$ and $50 \%$ ).

Nevertheless, it is possible to normalize the economic and environmental impact of the steel frame intervention by multiplying the cost of each smeared interventions per square meter by the area (without openings) of each façade, and comparing it with the total cost computed for the installation of the steel frame and low-emittance windows. The latter is about to $€ 6500, € 26100$ and $€ 29300$ for façades 0,1 and 2 respectively. 


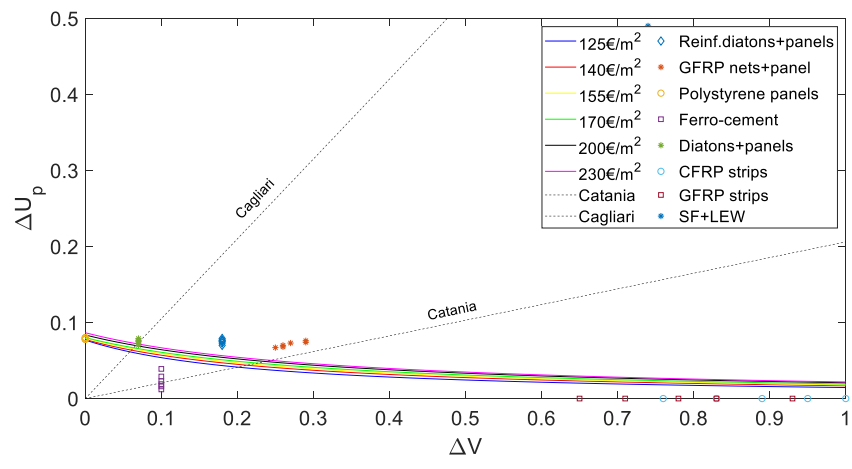

(a)

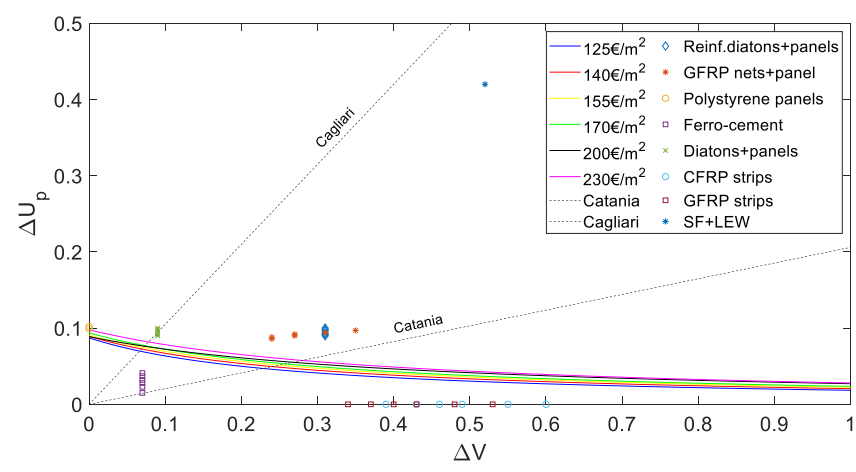

(c)

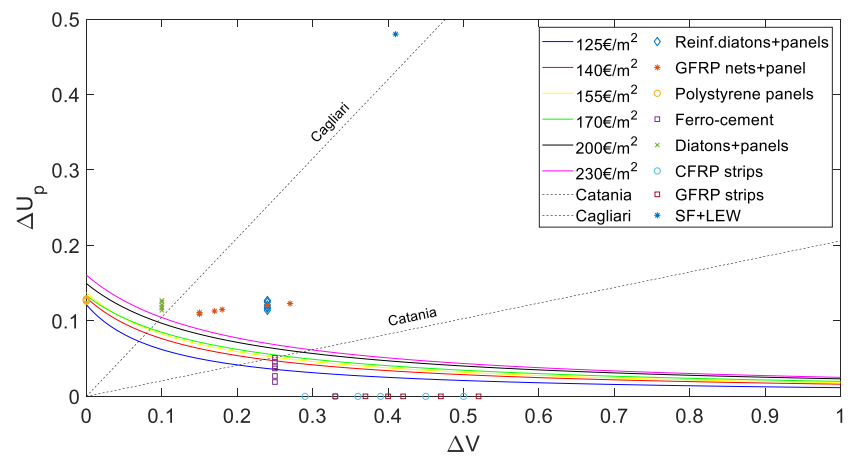

(e)

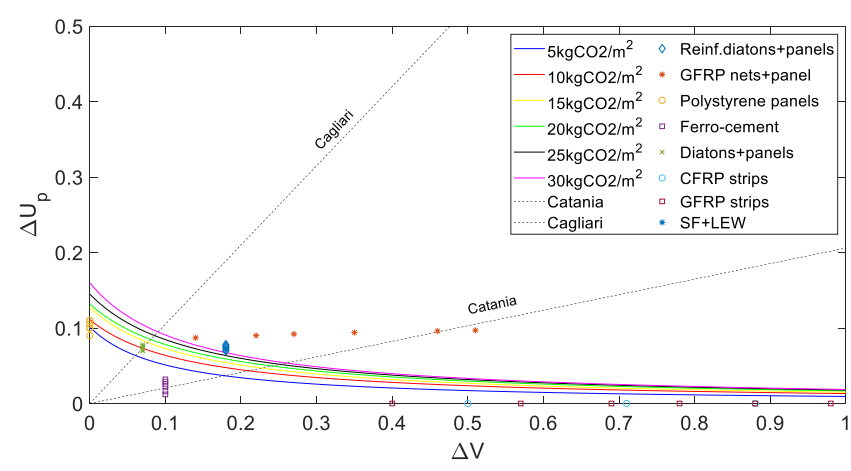

(b)



(d)

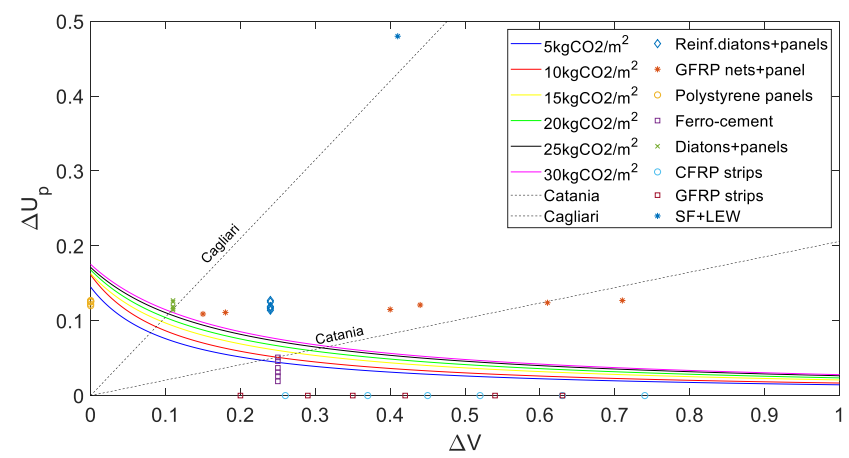

(f)

Figure 6 - Variation of periodic transmittance-variation of base shear isocost curves: façade 0, economic (a) and environmental (b); façade 1, economic (c) and environmental (d); façade 2, economic (e) and environmental $(f)$ impact. SF + LEW=hoop steel frame + low emittance windows.

The comparison between economic costs suggests that this intervention is more convenient than the individual and combined ones. Nevertheless, if a comparison in environmental terms is made, it is evident that the steel frame intervention has a greater impact in the amount of $\mathrm{kgCO}_{2 \text { eq }}$. The environmental costs are, in this case, 1365 $\mathrm{kgCO}_{2 \mathrm{eq}}, 5460 \mathrm{kgCO}_{2 \mathrm{eq}}$ and $6825 \mathrm{kgCO}_{2 \mathrm{eq}}$ for the three façades. Therefore, neglecting LCA the integrated intervention based on the use of a steel frame and the substitution of existing windows is more convenient in economic terms but less convenient in environmental terms, with the same variation of performance indicators. 


\subsection{Isocost economic and environmental curves considering periodic thermal transmittance}

In this paragraph analogous curves to those calculated in $\S 5.3$ are obtained. Here thermal transmittance is not calculated as mere function of the thermal resistance of each layer (which is in turn function of its thickness and thermal conductivity), but as periodic transmittance $U_{p}$.

The curves (Figure 6) show that the variation of periodic transmittance is lower than that of the normal transmittance. Indeed, the maximum variation is about 13\%. With the integrated approaches, the sensitivity in terms of periodic thermal transmittance is lower. The mechanical performances in case of reinforced diatons are much greater than the controlled-injection diatons (indicated as stars in Figure 6), with about tripled values of $\Delta V$ for all the three façades.

Again, the most convenient intervention is that with hoop steel frame and low emittance windows, with $\Delta V$ of $0.75,0.41$ and 0.47 for façades 0,1 and 2 respectively and $\Delta U_{p}$ by $0.48,0.52$ and 0.43 . Nevertheless, this integrated intervention would result too impacting in terms of GHG emissions if only the construction stage is considered.

\section{LCA and isoperformance curves}

This section discusses the analysis results of the integrated interventions with LCA and introduces isoperformance curves as further tool for decision-making. The results are reported - for the sake of brevity - only for façade 1 . Among all the integrated interventions described in Section 3, only those capable to provide an increment of $\Delta V$ equal to $20 \%$ and $30 \%$ are taken into account. Indeed, the seismic retrofitting according to the Italian standards [46] is attained, in case of façade 1, when the mechanical performance indicator (base shear $V$ ) increases by at least $20 \%$. Provided that the reference life of the building is 50 years, five typologies of interventions are then investigated: CFRP strips, GFRP strips, GFRP net plus polystyrene panels (thickness $5 \mathrm{~cm}$ ), reinforced diatons plus polystyrene panels, steel frame at the openings plus low-emittance windows. For each intervention, the economic and environmental costs are evaluated in the main phases of the whole life cycle of the building: construction, usage, maintenance and final disposal.

\subsection{Life cycle analysis at mesoscale level}

For each integrated intervention, the operations needed during the main phases of the building life cycle are analyzed. For instance, in case of CFRP and GFRP strips, during the construction phase, the cost of scaffolding, removal of old plaster, installation of strips, reconstruction of plaster and transportation plus disposal of residual building components have to be considered. Also when during the life cycle of the building some maintenance is foreseen, similar operations have to be taken into account. 
Table 1 - Life cycle analysis for each intervention.

Construction

Usage/maintenance

Disposal

\begin{tabular}{|c|c|c|c|}
\hline $\begin{array}{l}\text { CFRP } \\
\text { GFRP }\end{array}$ & $\begin{array}{l}\text { scaffolding } \\
\text { removing old plaster } \\
\text { installation of strips } \\
\text { plaster reconstruction } \\
\text { transportation of components } \\
\text { plaster disposal }\end{array}$ & $\begin{array}{l}\text { scaffolding } \\
\text { removing old plaster } \\
\text { removing old strips } \\
\text { installation of strips } \\
\text { plaster reconstruction } \\
\text { transportation of components } \\
\text { plaster disposal } \\
\text { strips disposal }\end{array}$ & $\begin{array}{l}\text { scaffolding } \\
\text { removing old plaster } \\
\text { removing old strips } \\
\text { plaster reconstruction } \\
\text { transportation of components } \\
\text { plaster disposal } \\
\text { strips disposal }\end{array}$ \\
\hline $\begin{array}{l}\text { Reinforced diatons and } \\
\text { polystyrene panels }\end{array}$ & $\begin{array}{l}\text { scaffolding } \\
\text { removing old plaster } \\
\text { installation of diatons } \\
\text { installation of polystyrene } \\
\text { panels } \\
\text { plaster reconstruction } \\
\text { transportation of components } \\
\text { plaster disposal }\end{array}$ & $\begin{array}{l}\text { scaffolding } \mathrm{x} 2 \\
\text { substitution of panels x2 } \\
\text { panels disposal x2 } \\
\text { transportation X2 } \\
\text { chemical analyses }\end{array}$ & $\begin{array}{l}\text { scaffolding } \\
\text { removing panels } \\
\text { disposal of components } \\
\text { transportation } \\
\text { chemical analyses }\end{array}$ \\
\hline $\begin{array}{l}\text { Steel frames and low- } \\
\text { emittance (PVC) windows }\end{array}$ & $\begin{array}{l}\text { scaffolding } \\
\text { removing old windows } \\
\text { glass and timber disposal } \\
\text { installation of steel hoops } \\
\text { windows installation } \\
\text { transportation }\end{array}$ & $\begin{array}{l}\text { localized re-painting against } \\
\text { corrosion } \\
\text { check of bolts tightening }\end{array}$ & $\begin{array}{l}\text { scaffolding } \\
\text { removing old windows } \\
\text { transportation } \\
\text { glass and PVC disposal } \\
\text { steel disposal }\end{array}$ \\
\hline GFRP net + polystyrene & $\begin{array}{l}\text { scaffolding } \\
\text { removing old plaster } \\
\text { plaster disposal } \\
\text { GFRP net installation } \\
\text { panels installation } \\
\text { transportation }\end{array}$ & $\begin{array}{l}\text { scaffolding } \mathrm{x} 2 \\
\text { panels substitution } \mathrm{x} 2 \\
\text { transportation } \mathrm{X} 2 \\
\text { chemical analyses x2 }\end{array}$ & $\begin{array}{l}\text { scaffolding } \\
\text { removing panels } \\
\text { removing GFRP net } \\
\text { panels and GFRP net disposal } \\
\text { transportation } \\
\text { chemical analyses x2 }\end{array}$ \\
\hline
\end{tabular}

For example, the strips are assumed to be replaced only once during the life cycle. The diatons are supposed to be never substituted during the life cycle, whereas the polystyrene panels, according to the indications of producers, should be renovated once every 15 years. As for the hoop steel frame intervention, only visual checks are foreseen for the steel elements, whereas the windows are supposed to be never replaced as their life is about 40/50 years. Finally, the GFRP net will be visually checked every 15 years. All these assumptions are synthetically reported in Table 1. The costs calculated for each step are collected to obtain the isocost curves considering the LCA of the façade, see Tables 2-3.

The manpower cost $M_{i}$ is calculated by multiplying the unitary cost $C_{h}(35 € / \mathrm{h})$ by the area of each intervention $A_{i}$ and by the time required for the realization/disposal of it $t_{r / d}$ :

$$
M_{i}=C_{h} \cdot A_{i} \cdot t_{r / d}
$$


Table 2 - Material and manpower costs for the integrated interventions [42].

\begin{tabular}{ccl} 
CFRP & 112.4 & $€ / \mathrm{m}^{2}$ \\
\hline GFRP & 91.7 & $€ / \mathrm{m}^{2}$ \\
\hline Plaster & 21 & $€ / \mathrm{m}^{2}$ \\
\hline Polystyrene panel & 149 & $€ / \mathrm{m}^{3}$ \\
\hline GFRP net & 2200 & $€ / \mathrm{m}^{3}$ \\
\hline PVC windows & 322 & $€ / \mathrm{m}^{2}$ \\
\hline Reinforced diatons & 80 & $€ / \mathrm{m}^{2}$
\end{tabular}

Table 3 - Costs involved during the life cycle according to Table 1.

\begin{tabular}{lcc} 
Transportation $\left(60 \mathrm{~m}^{3}\right)$ & 200 & $€$ \\
\hline $\begin{array}{l}\text { Chemical analysis for recycling } \\
\text { polystyrene panels }\end{array}$ & 250 & $€$ \\
\hline Scaffolding $\left(\mathrm{A}=281 \mathrm{~m}^{2}\right)$ & 4215 & $€$ \\
\hline Disposal of non-ferrous waste & 80 & $€ / \mathrm{m}^{3}$ \\
\hline Disposal of ferrous waste & 15 & $€ / \mathrm{m}^{3}$ \\
\hline PVC disposal & 0.34 & $€ / \mathrm{kg}$ \\
\hline Glass disposal & 0.9 & $€ / \mathrm{kg}$
\end{tabular}

\subsection{Economic and environmental isoperformance curves considering LCA}

Isoperformance curves are design curves in which economic and environmental costs are reported, for a fixed increment of seismic or energy indicator. Such curves are useful as the designer can have a direct information about the most beneficial integrated intervention for a target thermal or seismic performance improvement.

The seismic risk index $I_{R}$ is defined as the ratio between the façade shear base strength $V$ (capacity) and the standard required base shear strength $V_{R}$ (demand):

$$
I_{R}=\frac{V}{V_{R}}
$$

The increment of seismic performance indicator $\Delta V$ can be seen as design increment required to get at least a unitary risk index $I_{R}$. For example, if in the as-built configuration the risk index is $I_{R}=0.6$, one has to ensure an increment of base shear $\Delta V$ given by the pushover analysis such that $I_{R}=1$. For the case under examination, $I_{R}$ oscillates between 0.2 and 0.3 .

When the entire life cycle of the building is computed, the calculation of the economic curves for each intervention is more significant since it includes the usage and disposal phases, often decisive for the level of investments on the structural component. It is evident that to consider only the construction phase causes errors of assessment since the construction cost for an intervention can be much greater than another, but the corresponding usage and disposal costs could be extremely lower. 




(a)

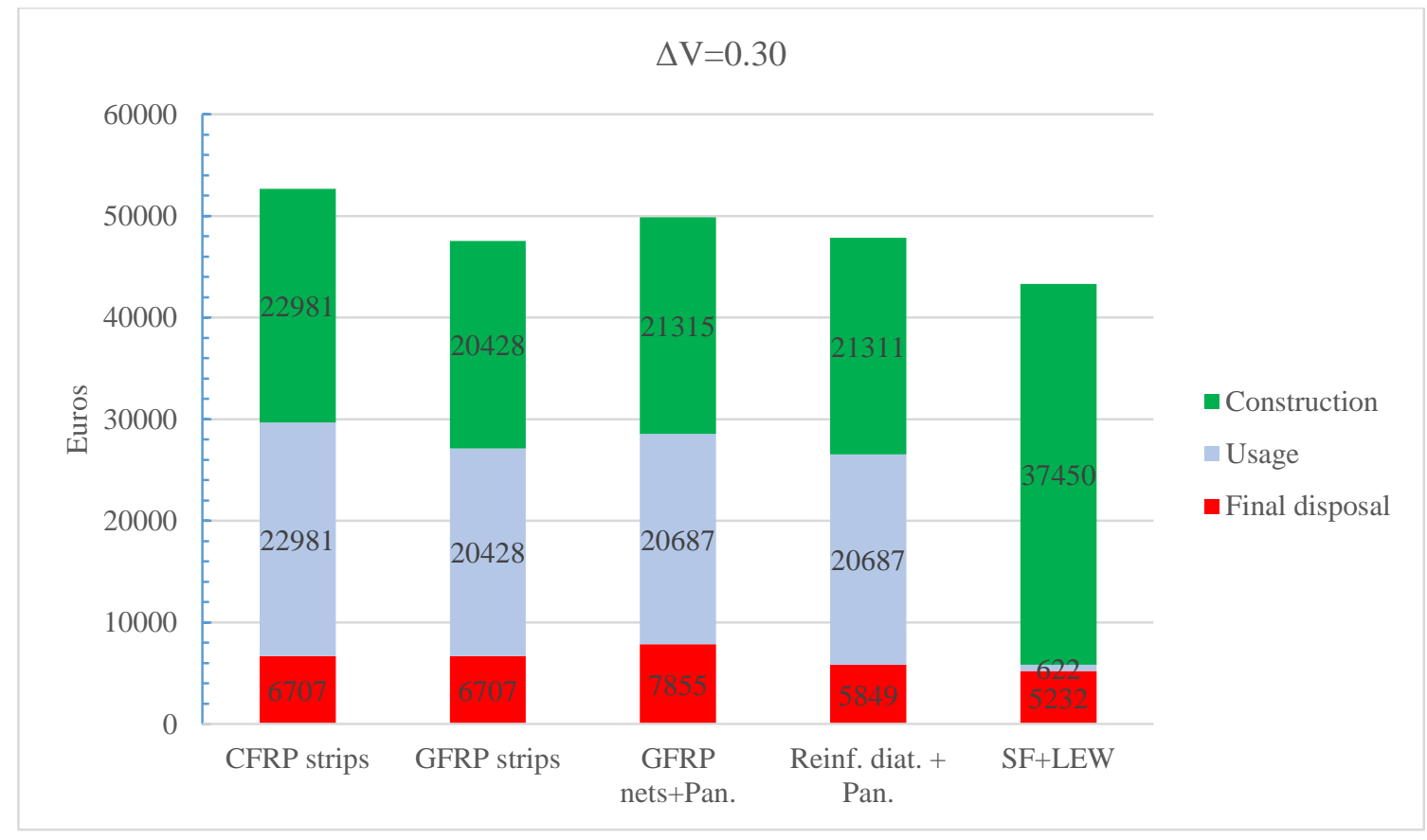

(b)

Figure 7 - Economic costs computed with LCA with $\Delta V=20 \%(a)$ and $\Delta V=30 \%(b)$

The intervention with hoop frames and low-emittance windows is the most expensive in the construction phase, but for $\Delta V=30 \%$ (Figure $7 \mathrm{~b}$ ) is the most beneficial in economic terms, and its total cost is equivalent to the others for $\Delta V=20 \%$ (Figure $7 \mathrm{a}$ ). 
As for the environmental curves, the amount of $\mathrm{CO}_{2 \mathrm{eq}}$ emissions is computed for each phase. For the disposal phase, the net saving of emissions is due to the recycling operations of the materials and is listed in Table 4. Figure 8 displays the $\mathrm{kgCO}_{2 \mathrm{eq}}$ emissions for each intervention separately considering the main phases of the life cycle. Positive values in this graph indicate the expenditure for environmental cost during the construction and usage phases, and negative values indicate recovery of environmental cost during the final disposal phase. The interventions with GFRP and CFRP strips are those with less impact in terms of $\mathrm{CO}_{2 \text { eq }}$ emissions saving, indeed they are not associated to any environmental recovering during the phase disposal, since the amount of material is negligible (thickness of strips of few millimeters). The best intervention results then to be the installation of hoop steel frame and low-emittance windows. Indeed, this intervention has a very low impact in environmental terms due to the recyclability of steel, glass and PVC (Table 4).

Table 4 - Saved emissions of $\mathrm{CO}_{2 e q}$ thanks to the recycling of disposed materials.

\begin{tabular}{|c|c|l|}
\hline CFRP & 2.80 & $\mathrm{kgCO} 2 \mathrm{eq} / \mathrm{kg}$ \\
\hline GFRP & 0.60 & $\mathrm{kgCO} 2 \mathrm{eq} / \mathrm{kg}$ \\
\hline Plaster & $\begin{array}{c}\text { Recycled as inert } \\
\text { material }\end{array}$ & $\mathrm{kgCO} 2 \mathrm{eq} / \mathrm{kg}$ \\
\hline Polystyrene net & 7.85 & $\mathrm{kgCO} 2 \mathrm{eq} / \mathrm{kg}$ \\
\hline GFRP net & 0.60 & $\mathrm{kgCO} 2 \mathrm{eq} / \mathrm{kg}$ \\
\hline PVC & 1.39 & $\mathrm{kgCo} 2 \mathrm{eq} / \mathrm{kg}$ \\
\hline Glass & 0.57 & $\mathrm{kgCO} 2 \mathrm{eq} / \mathrm{kg}$ \\
\hline Steel & 1.64 & $\mathrm{KgCo} 2 \mathrm{eq} / \mathrm{kg}$ \\
\hline
\end{tabular}

Analogously to a design increment of seismic performance indicator $\Delta V$, one can define a design decrement considering the target value of thermal transmittance required by the national standards. Defined as $U_{t}$ this target value, the design decrement (in absolute value) $\Delta U$ is:

$$
\Delta U=\frac{\left|U_{t}-U_{0}\right|}{U_{0}}
$$

For the case under examination, the Italian standards [48] indicate as target for 2021 values of $U_{t, m}=0.4 \mathrm{~W} / \mathrm{m}^{2}$ and $U_{t, w}=3.2 \mathrm{~W} / \mathrm{m}^{2} \mathrm{~K}$ for walls and windows respectively (climate zone B). The consequent weighted thermal transmittance would be $U_{t}=1.3 \mathrm{~W} / \mathrm{m}^{2} \mathrm{~K}$, therefore the required decrement would be $\frac{(2.72-1.3)}{2.72} \cdot 100=52 \%$ Nevertheless, such a variation is not attainable through the proposed interventions (for instance, it would be necessary to provide a thickness of insulating panels of over $20 \mathrm{~cm}$ ). Therefore, a target variation of $\Delta U=35 \%$ is considered. (a) 




(b)

Figure 9 displays the environmental and economic costs: in this case, the intervention with hoop steel frame and low emittance windows is less expensive and environmentally impacting than the others, resulting therefore the most beneficial.



(a) 




(b)

Figure 8-Environmental costs computed with LCA with $\Delta V=20 \%($ a) and $\Delta V=30 \%(b)$.

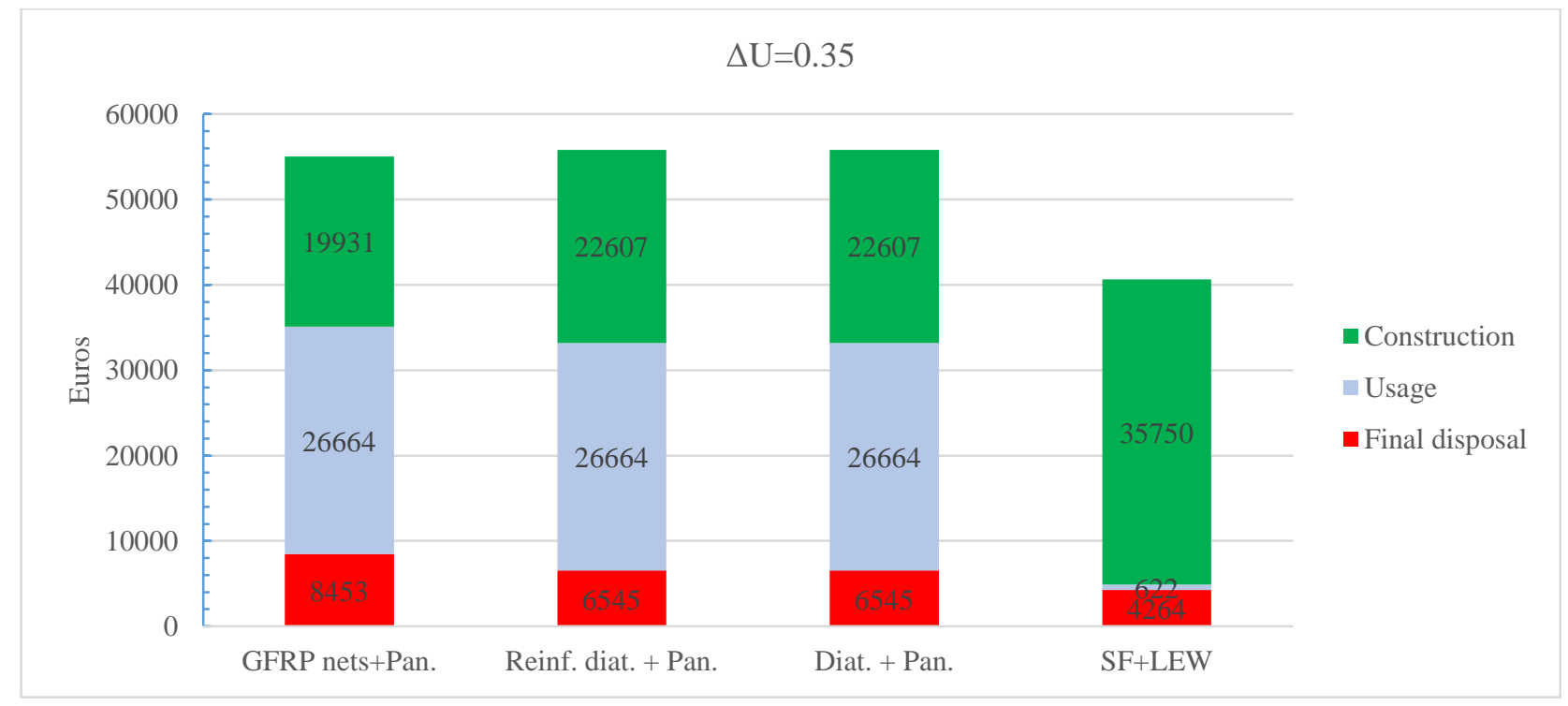

(a) 


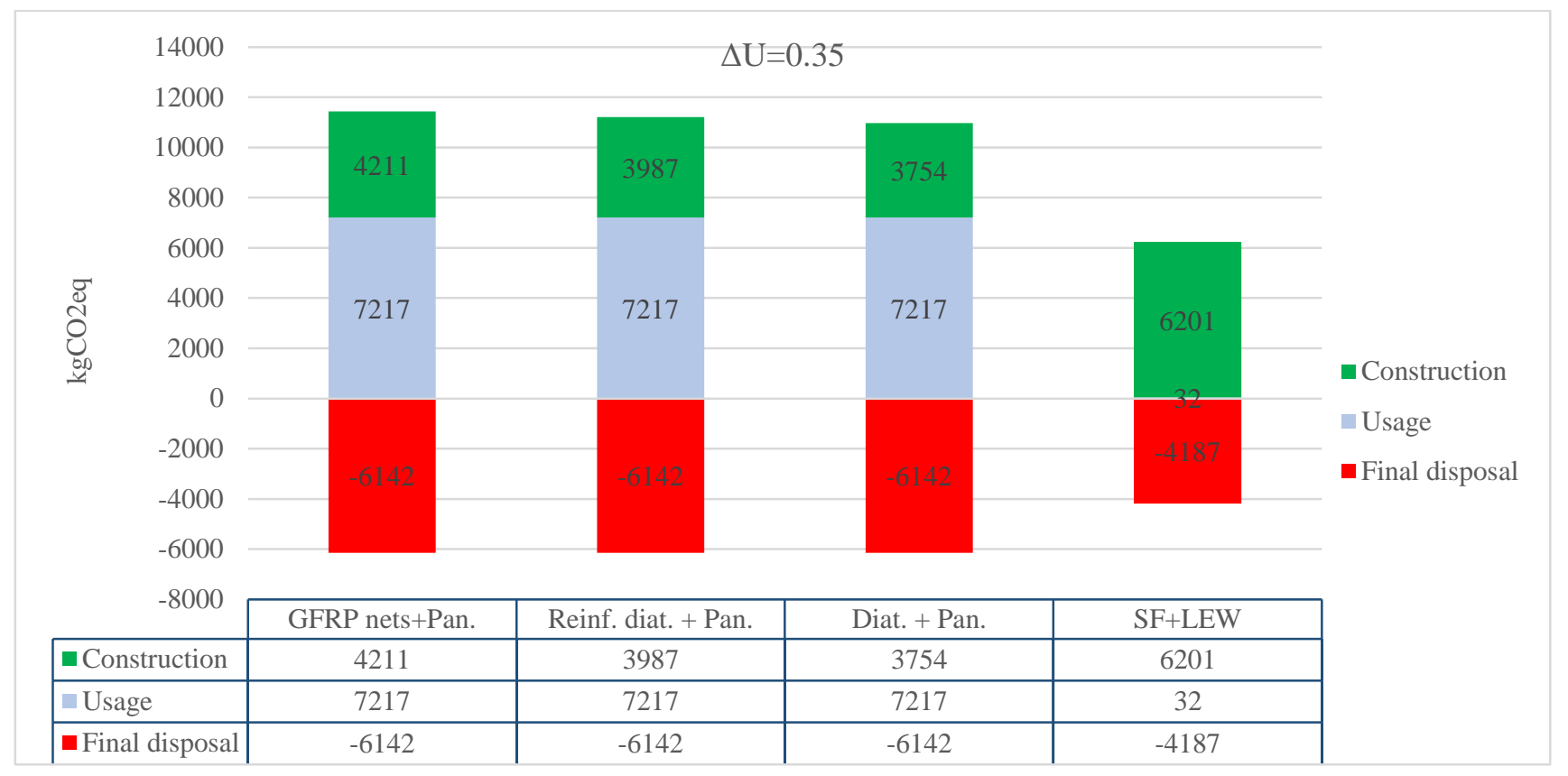

(b)

Figure 9 - Economic (a) and environmental (b) costs computed with LCA with $\Delta U=35 \%$

\subsection{Comparisons between integrated interventions with and without LCA}

A comparison between the several integrated interventions with or without LCA can be made by comparing the isoperformance curves shown in Figure 10. For both economic and environmental costs, there is a remarkable difference when LCA is considered. If the improvement of seismic indicator is by $20 \%$, the most expensive intervention is the GFRP net coupled with polystyrene panels if LCA is considered, whereas the most expensive computing only the construction stage is undoubtedly the hoops steel frame coupled with low-emittance windows. This remark is more noticeable with $\Delta V=30 \%$ (Figure 10b), where the last intervention is the most expensive in the construction phase and the less expensive considering LCA. It is therefore recommended to perform an LCA, although not simple, to assess the economic and environmental costs. 


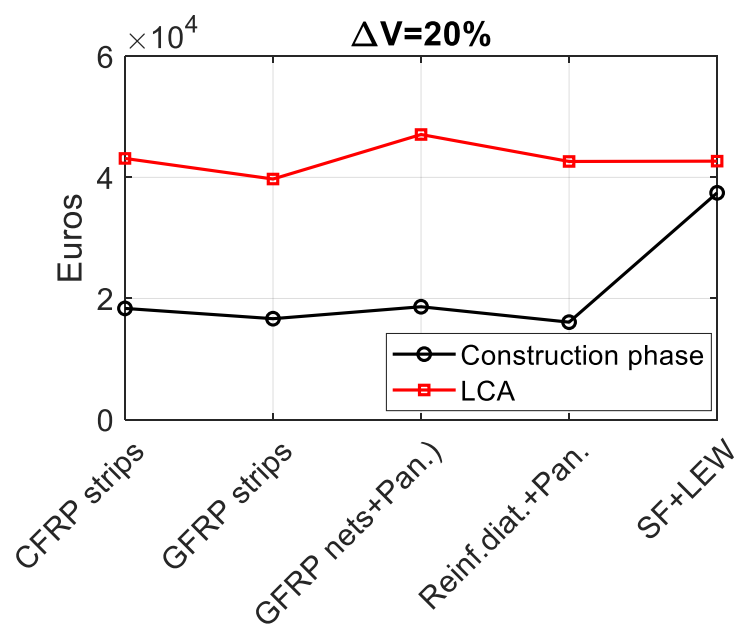

(a)

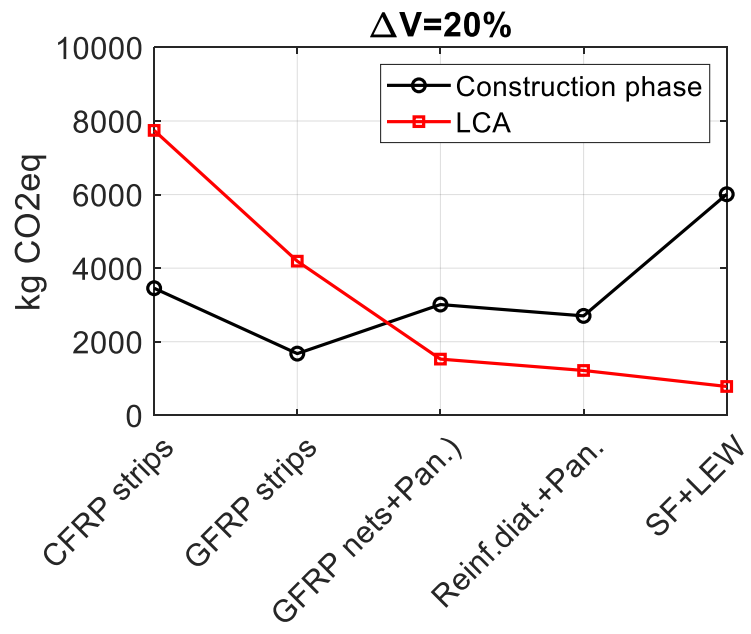

(c)

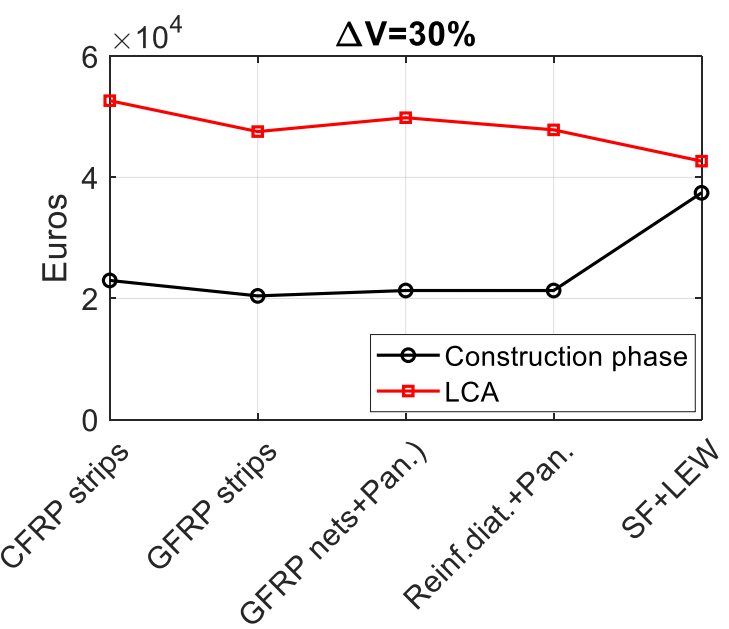

(b)

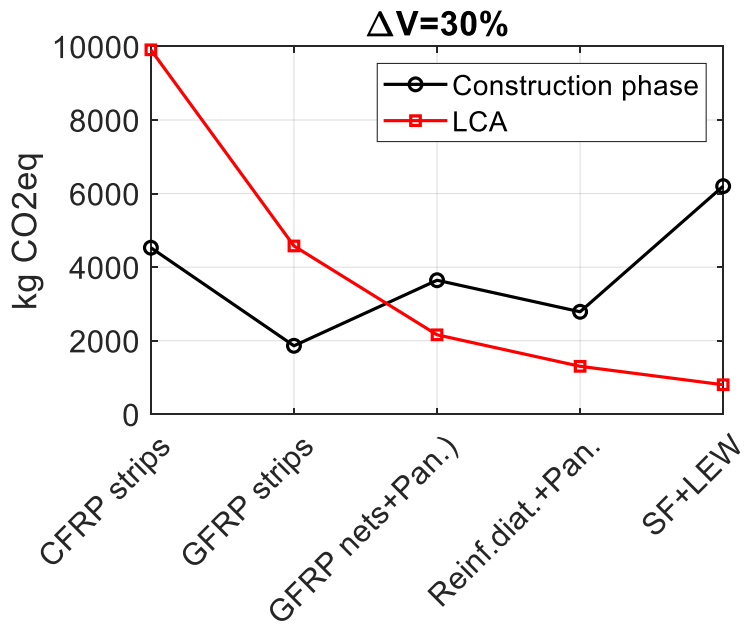

(d)

Figure 10 - Comparisons between integrated interventions with and without LCA: economic $(a, b)$ and environmental $(c, d)$ costs.

When the $\mathrm{CO}_{2 \text { eq }}$ emissions are evaluated, the recyclability of building materials allows a strong reduction of this impact category, as visible in Figure 10c, d. The recyclability of steel, glass and PVC implies a saving of $\mathrm{CO}_{2 \mathrm{eq}}$ emissions rather relevant. Therefore, the total amount of $\mathrm{CO}_{2 \mathrm{eq}}$ emissions decreases for the interventions with GFRP net and polystyrene panels, for the hoops steel frame and low emittance windows and for the reinforced diatons and polystyrene panels, recovering part of the emissions due to the construction phase. This aspect is essential for assessing the judgment of an integrated intervention.

Naturally, the isoperformance curves can be also obtained through the desired variation of thermal transmittance, instead of the variation of base shear. Figure 11 displays the comparison between the isoperformance curves considering a reduction by $35 \%$ of thermal transmittance, still showing that the intervention with steel frame and low emittance windows is more convenient when taking into account LCA. 


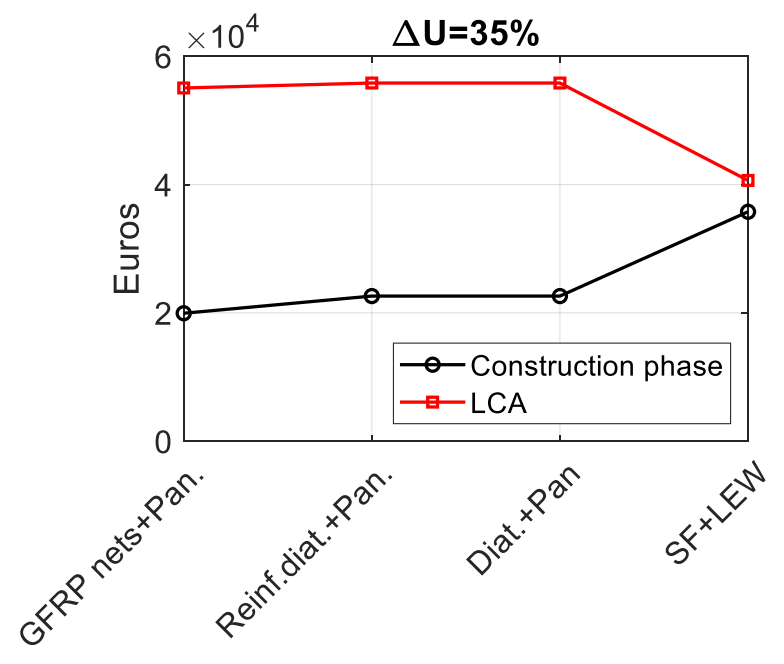

(a)

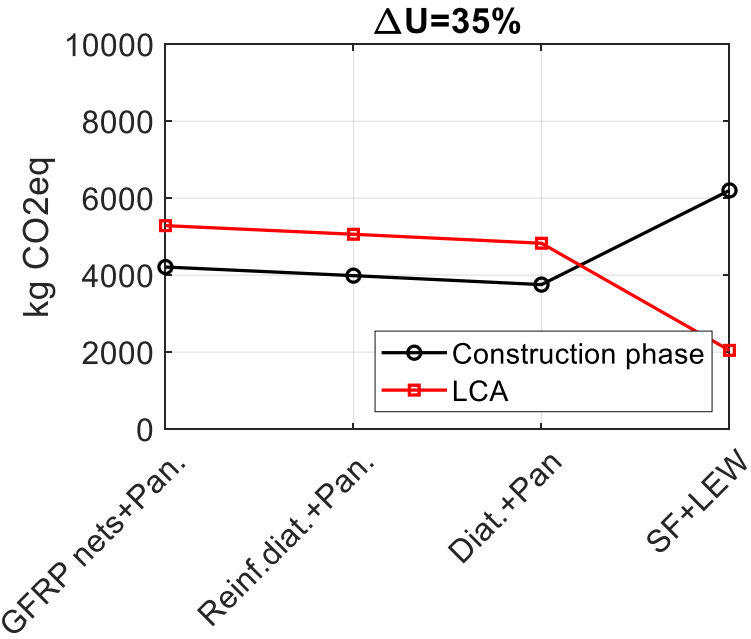

(b)

Figure 11 - Comparisons between integrated interventions with and without LCA: economic (a) and environmental (b) costs with design decrement of thermal transmittance by $35 \%$.

\section{Conclusions}

A procedure to design integrated interventions for the improvement of seismic and energy performance of buildings at mesoscale (façade) level has been proposed. The procedure, useful for different building types, consists in the calculation of isocost curves in economic and environmental terms. Through them, it is possible to evaluate the increment of performance indicators (base shear, ductility, thermal transmittance, periodic thermal transmittance) for each intervention and for each unitary cost. This information can be used by both public administrations, decision-makers and private owners.

They can choose the retrofitting intervention, given the level of improvement and the available budget. Moreover, the proposed approach is based on isoperformance curves: fixing a threshold variation of seismic or energy performance, it provides the economic and environmental costs for each intervention. These curves can be obtained considering or not LCA. The procedure, applied to a case study of a masonry building, has been shown considering the LCA results in the entire life of the building. To take into account only the construction phase causes errors of assessment, since the usage and disposal costs vary significantly for each intervention.

The following remarks for the case study can be done:

- CFRP and GFRP give high structural performances, indeed the increment of base shear of façade 0 is by about $90 \%$ and by about $40 \%$ respectively for façades 1 and 2 ;

- The polystyrene panels should be coupled with interventions that increase the seismic indicators. The former guarantee a reduction of transmittance by about $30 \%$ for all the façades, with limited variations of $\Delta U$ in function of the cost, due to the large windows area that limits the beneficial effect of the external coating. 
- Given a fixed budget, without considering LCA, the best combined interventions of the case study are the reinforced diatons plus polystyrene panels and GFRP plus polystyrene panels.

- Considering LCA, the interventions with GFRP and CFRP strips are those with less impact in terms of $\mathrm{CO}_{2 \text { eq }}$ emissions: they are not associated to any environmental recovery during the phase disposal since the amount of material is negligible (thickness of strips of few millimeters).

- Performing LCA, the best intervention consists in the installation of hoops steel frames and low-emittance windows. This solution, considering the high recyclability of steel, glass and PVC, results to a low impact integrated intervention.

The methodology here presented can be easily extended from masonry buildings to other building materials, such as r.c., timber and steel structures. The extension is possible by properly adapting the selection of the seismic performance indicator, which can be, for instance, the percentage reduction of an interstorey drift when a global analysis is considered.

\section{Acknowledgements}

The Authors thank the Department of Civil Protection that financed this research activity in the RELUIS project (2020) and Mr. Nicola Franceschi for the calculations performed on the case study. The support of ReLuis DPC Department of Civil Protection, project: ReLUIS-DPC 2019-2021 -WP5 - Rapid, low-impact and integrated retrofit interventions are acknowledged.

Flavio Stochino also acknowledges the support of the Autonomous Region of Sardinia under grant P.O.R. SARDEGNA 2014-2020, CCI: 2014- IT05SFOP021, Project: Retrofitting, rehabilitation and requalification of the historical cultural architectural 506 heritage (R3-PAS).

\section{REFERENCES}

[1] International Organisation for Standardization, ISO 14040-Environmental Management - life cycle assessment - principles and framework. . Geneva, Switzerland, 2006.

[2] Eurocode 6: Design of masonry structures - Part 1-1: General rules for reinforced and unreinforced masonry structures, No Title. . The European Union Per Regulation 305/2011, Directive 98/34/EC, Directive 2004/18/EC.

[3] M. W. Ahmad, M. Mourshed, D. Mundow, M. Sisinni, and Y. Rezgui, Building energy metering and environmental monitoring - A state-of-the-art review and directions for future research. Energy and Buildings, 120, 85-102, 2016.

[4] T. Hong, Z. Wang, X. Luo, and W. Zhang, State-of-the-art on research and applications of machine learning in the building life cycle. Energy and Buildings, 212, 109831, 2020.

[5] X. Cao, X. Dai, and J. Liu, Building energy-consumption status worldwide and the state-of-the-art technologies for zero-energy buildings during the past decade. Energy and Buildings, 128, 198-213, 
2016.

[6] F. Solarino, D. Oliveira, and L. Giresini, Wall-to-horizontal diaphragm connections in historical buildings: A state-of-the-art review. Engineering Structures, 199, 2019.

[7] L. Giresini, F. Solarino, O. Paganelli, D. V. Oliveira, and M. Froli, One-sided rocking analysis of corner mechanisms in masonry structures: influence of geometry, energy dissipation, boundary conditions. Soil Dynamics and Earthquake Engineering, 123, 357-370, 2019.

[8] C. Casapulla, L. Giresini, L. U. Argiento, and A. Maione, Nonlinear Static and Dynamic Analysis of Rocking Masonry Corners Using Rigid Macro-Block Modeling. International Journal of Structural Stability and Dynamics, 19, 1950137, 2019.

[9] L. Giresini, M. Sassu, and L. Sorrentino, In situ free-vibration tests on unrestrained and restrained rocking masonry walls. Earthquake Engineering \& Structural Dynamics, 47, 3006-3025, 2018.

[10] V. Alecci and M. De Stefano, Building irregularity issues and architectural design in seismic areas. Frattura ed Integrità Strutturale, 13, 161-168, 2019.

[11] L. Giresini, B. Pantò, S. Caddemi, and I. Caliò, Out-of-plane seismic response of masonry façades using discrete macro-element and rigid block models. , in COMPDYN 2019 7th ECCOMAS Thematic Conference on Computational Methods in Structural Dynamics and Earthquake Engineering, 2019, 702-717, .

[12] P. Asadi and I. Hajirasouliha, A practical methodology for optimum seismic design of RC frames for minimum damage and life-cycle cost. Engineering Structures, 202, 109896, 2020.

[13] B. Gencturk, K. Hossain, and S. Lahourpour, Life cycle sustainability assessment of RC buildings in seismic regions. Engineering Structures, 110, 347-362, 2016.

[14] M. Sassu, L. Giresini, E. Bonannini, and M. L. Puppio, On the Use of Vibro-Compressed Units with BioNatural Aggregate. Buildings, 6, 2016.

[15] A. Caverzan, M. Lamperti Tornaghi, and P. Nigro, Proceedings of the SAFESUST Workshop. , in SAFESUST Workshop, 2016.

[16] A. Audenaert, S. H. De Cleyn, and B. Vankerckhove, Economic analysis of passive houses and low-energy houses compared with standard houses. Energy Policy, 36, 47-55, 2008.

[17] G. M. Calvi, L. Sousa, and C. Ruggeri, Energy Efficiency and Seismic Resilience: A Common Approach. , in Multi-hazard Approaches to Civil Infrastructure Engineering, P. Gardoni and J. M. LaFave, Eds. Springer International Publishing, 2016, 165-208, .

[18] M. Sassu, F. Stochino, and F. Mistretta, Assessment method for combine structural and energy retrofitting in masonry buildings. Buildings, 7, 2017.

[19] F. Mistretta, F. Stochino, and M. Sassu, Structural and thermal retrofitting of masonry walls: An integrated cost-analysis approach for the Italian context. Building and Environment, 155, 127-136, 2019.

[20] L. Giresini, S. Paone, and M. Sassu, Integrated Cost-Analysis Approach for Seismic and Thermal Improvement of Masonry Building Façades. Buildings, 10, 2020.

[21] Italian Institute of Geophysics and Volcanology: Map of seismic hazard. Available online: https.www.ingv.it (accessed on May 26th 2020). . .

[22] EN ISO 15927-6 Hygrothermal performance of buildings - Calculation and presentation of climatic data 
- Part 6: Accumulated temperature differences (degree-days). , 2007. .

[23] UNI EN ISO 6946:2008 Componenti ed elementi per edilizia - Resistenza termica e trasmittanza termica Metodo di calcolo. .

[24] UNI 10351:1994 Building materials. Thermal conductivities and vapour permeabilities. .

[25] EN ISO 13786:2017, Thermal performance of building components - Dynamic thermal characteristics Calculation methods. . 2017.

[26] UNI EN ISO 10211:2008 Thermal bridge in buildings - Thermal flow and surface temperatures Calculation methods. .

[27] EN ISO 10077-1:2006 Thermal performance of windows, doors and shutters - Calculation of thermal transmittance...

[28] MATLAB. version 9.4.0.813654 (R2018a). The MathWorks Inc., Natick, Massachusetts, 2018. . .

[29] C. Casapulla, L. Cascini, F. Portioli, and R. Landolfo, 3D macro and micro-block models for limit analysis of out-of-plane loaded masonry walls with non-associative Coulomb friction. Meccanica, 49, 1653-1678, 2014.

[30] L. Giresini, M. L. Puppio, and F. Taddei, Experimental pull-out tests and design indications for strength anchors installed in masonry walls. Materials and Structures, 2020.

[31] L. Giresini and C. Butenweg, Earthquake Resistant Design of Structures According to Eurocode 8. , in Structural Dynamics with Applications in Earthquake and Wind Engineering, 2019, 197-358, .

[32] L. Giresini, Design strategy for the rocking stability of horizontally restrained masonry walls. , in COMPDYN 2017 6th ECCOMAS Thematic Conference on Computational Methods in Structural Dynamics and Earthquake Engineering, Rhodes Island, Greece, 15-17 June 2017., 2017.

[33] C. Casapulla, P. Jossa, and A. Maione, Rocking motion of a masonry rigid block under seismic actions: A new strategy based on the progressive correction of the resonance response | II moto sotto sisma del blocco murario: Analisi per progressiva correzione della risposta in risonanza. Ingegneria Sismica, 27, 35-48, 2010.

[34] C. Casapulla and A. Maione, Critical Response of Free-Standing Rocking Blocks to the Intense Phase of an Earthquake. International Review of Civil Engineering, 8, 1-10, 2017.

[35] Ministero delle infrastrutture e dei trasporti, Circolare 21 gennaio 2019, $n$. 7 Istruzioni per l'applicazione dell' «Aggiornamento delle "Norme tecniche per le costruzioni"», 35, . 2019, 1-337, .

[36] SETAC, Life-cycle assessment in building and construction: a state-of-the-art report. . 2003.

[37] T. Ramesh, R. Prakash, and K. K. Shukla, Life cycle energy analysis of buildings: An overview. Energy and Buildings, 42, 1592-1600, 2010.

[38] B. Palacios-Munoz, L. Gracia-Villa, I. Zabalza-Bribián, and B. López-Mesa, Simplified structural design and LCA of reinforced concrete beams strengthening techniques. Engineering Structures, 174, 418-432, 2018.

[39] M. Buyle, J. Braet, and A. Audenaert, Life cycle assessment in the construction sector: A review. Renewable and Sustainable Energy Reviews, 26, 379-388, 2013.

[40] D. Romano, C. Arcarese, and Al., Italian Greenhouse Gas Inventory 1990-2015- National Inventory 
Report 2017...

[41] Emission factors in kg co2-equivalent per unit:

https://www.winnipeg.ca/finance/findata/matmgt/documents/2012/682-2012/682-2012_Appendix_HWSTP_South_End_Plant_Process_Selection_Report/Appendix\%207.pdf. . .

[42] Bulletin of unitary costs in Tuscany Region (Prezziario Lavori Pubblici Regione Toscana). . 2020.

[43] Gruppo sismica s.r.I., Computer Program for masonry buildings - 3D MACRO. . 2018.

[44] L. Giresini, A. Gioeli, and M. Sassu, Seismic reinforcement of a r.c. Building with external steel frameworks: The case of the primary school XXV April of Arcola (Italy). Advanced Materials Research, 834-836, 697-700, 2013.

[45] A. De Falco, M. Froli, L. Giresini, M. L. Puppio, and M. Sassu, A proposal for the consolidation of a r.c. social housing by means of external hybrid steel-glass frameworks. Applied Mechanics and Materials, 638-640, 3-8, 2014.

[46] Decreto Ministeriale 17/01/2018, Italian Technical Standards for buildings (Nuove Norme Tecniche per le Costruzioni, in italian). . 2018.

[47] General Assembly of the Superior Council of Public, Circolare attuativa del D.M. 17/01/2018 (NTC 2018). 2019.

[48] S. ordinario n. 39 alla G. UFFICIALE, Requisiti specifici per gli edifici esistenti soggetti a riqualificazione energetica. Appendice B, all. 1, cap. 4. . 2015. 